\title{
Assessment of Industrial Safety Education Programmes In Manufacturing Industries In Kaduna And Niger States Of Nigeria
}

\author{
Atsumbe, B. ${ }^{1}$. Ohize, E.J ${ }^{1}$. Abutu, Francis ${ }^{1}$, Amine J. D ${ }^{2}$ \\ 1.Department of Industrial \& Technology Education, Federal University of Technology,Minna Niger State \\ Nigeria \\ 2.Department of Mechanical Engineerin, University of Agiculture,Makurdi, Benue State Nigeria
}

\begin{abstract}
Loss of working hours, low productivity and the loss of human and material resources due to negligence of safety and industrial safety education programme has become an incessant problem in manufacturing industries. This research study therefore focused on the assessment of industrial safety education programmes in the manufacturing industries of Kaduna and Niger states of Nigeria. The study sought to identify the industrial safety education training needs of the industries; the potential sources of industrial accidents in workshops/laboratories of manufacturing industries and the suitable instructional methods used by the industries to ensure safety and accident prevention in the industries. A 45 item questionnaire was used to collect data from management staff and factory workers from 24 manufacturing industries spread across Kaduna and Niger states of Nigeria. Mean $(\bar{X})$ and Standard Deviation (S.D) were used for data analysis. The study among others found that: a conducive working environment greatly reduce potential sources of accidents and identifies appropriate industrial safety education training needs of the industries in addition to the instructional methods adopted. The study also recommended that: Federal Government should ensure monitoring and strict compliance with factories laws to save human and material resources and to create a conducive working environment for industrial workers in Nigeria.
\end{abstract}

\section{Introduction}

Strict adherence to industrial safety has become a major challenge in the manufacturing industries of Nigeria because of its effects on overall productivity and production cost. Ofuonye (2004) lamented on the pathetic situation of incessant dozens of industrial accidents occurring in manufacturing industries in Nigeria on a monthly basis leading to loss of life, injuries, damage to material resources and hindrance to achievement of production target. It has been observed that a lot of accidents occur because of lack of safety awareness. Men fall from ladders, operate their machines without a guard, drop objects on their toes, or cut their hands because of misuse of tools. Some even get to the extent of crushing their fingers in between moving sprockets and some rendered blind because of wrong settings of timing valves among others. According to Atsumbe (1996) all these are the results of unsafe acts- the reason for these being that there have not been complete instructions or what you may term safety education on safe practices. Safety education can take different forms for example by having awareness meetings, posters, safety booklets, films, special classroom sessions, and some safety contacts with safety specialist and supervisors. Some industrial organizations use what is termed mass educational method. However it is important to stress that when industries embark on thorough and aggressive safety education the following are bound to ensure, compensation and medical payments, reduced damage to equipment and products, production delays and unnecessary subtractions from production profits are reduced to the barest minimum. Further to this Atsumbe (2006) observed that correct safety education results in good community relations, lower employee turnover and absenteeism, better employee morale, higher production targets and steadier work. Manufacturing industries can be described as the industries that focus on the transformation of materials and information into goods for the satisfaction of human needs.

Godbey (1979) described industrial safety as the science which investigates the facts by logic and knowledge to ensure that personnel and equipment operate harmoniously in a defined environment which will not encounter unexpected or inadvertent events that would result in injury or damage to either of them. Safety education is a control process and a procedure which must be identified for the prevention and correction of unsafe acts and conditions. Mewis (1995) emphasized the need for safety education in the industries to prevent accidents and injuries. He also stated that the implementation of safety education programmes have contributed immensely to the declining rate of accidents and injuries in industrial work places. Industrial safety education programme in the industry is a very important component which cannot just be ignored by the industry but must be enforced to the fullest to prevent injuries to workers, loss of life and damage to materials, tools, equipment and machines. Miller (1998) stated that it is difficult to teach and implement industrial safety education 
programme without first giving thought to the causes of factory accidents. He also confirmed that factory workers, students, safety engineers and teachers of safety must have a thorough understanding of how accidents occur before they can identify an unsafe condition and correct the situation. A good safety education programme is based on adequate instruction in the operation and maintenance of existing tools, equipments and machineries.

Jain (2010) attributed the high rate of accidents in industries to poor attitude of workers towards safety practices, poor attitudes of employers towards provision of safety awareness training courses and incomplete instructions on safe practices and technical know-how on the operation of tools, equipment and machineries. He also stressed that the absence of safety education have made workers operate machines without a guard, drop objects on their toes, or cut their hands because of misuse of tools. Jain(2006) noted that lack of safety education have led several workers into unsafe acts such as operating machines which they are not familiar with, lifting heavy loads which is above their strength in an incorrect manner, adjusting moving belts, sprockets and timing chains which has led to fatal accidents. He further emphasized that a good industrial safety education programme for manufacturing industries should involve both mass industrial safety education methods as well as personalized industrial safety education training method. Mass industrial safety education methods involve having meetings, use of posters, safety booklets, films, special classroom sessions and some safety contacts by safety teachers, specialists and supervisors; while the personalized industrial safety education training method permits the conversion of safety generalities into specific safe practices that apply to a specific jobs and to the individual doing the job. Personalized safety training is more effective since it permits consideration of the worker's rate of learning, his interests, his natural ability and his physical limitations at work.

According to Riggs (2010) industrial safety education programme will be ineffective if attempts are made to control accidents without first creating a proper safety philosophy, teaching safety principles and eliminating misconceptions about the causes of accidents. To prevent accidents and ensure safety at work, safety rules have to be enforced, safe working conditions developed and workers trained to do the job safely. Supervisors, safety teachers and engineers must believe that accidents are caused and they can also be prevented. However, manufacturing industries in Nigeria in a bid to maximize cost go the extra mile to ensure over utilization of human and material resources with little regard to industrial safety education which makes personnel and material resources vulnerable to accident and loss of life. Apagu, Bulama and Diraso (2000) found out that industrial accidents and mishaps can generally be attributed to environmental conditions, human behaviours, and improper use of tools/machines. Specifically the accidents are tied to the following five conditions: insufficient skill of the workers, lack of knowledge of safety education, poor work habits and attitudes, unsafe behaviours and environmental hazards. Equipment in the industries need to be protected, while workers and employers of labour need to have sound knowledge of industrial safety education to minimize loss of life, materials and waste of working hours due to industrial accidents. It is the pathetic situation of constant occurrence of industrial accidents in manufacturing industries in Nigeria due to the incessant negligence and poor attitude towards industrial safety education programme that necessitated this study.

\section{Research Questions}

Three research questions guided the study:

1. What are the industrial safety education training needs of the industrial workers in Kaduna and Niger states of Nigeria?

2. What are the potential sources of industrial accidents in workshops/laboratories of manufacturing industries?

3. What are the suitable instructional methods used by the industries to ensure safety and accident prevention?

\section{Methodology}

The study used a survey research design which focused on the assessment of industrial safety education programme in manufacturing industries of Kaduna and Niger states of Nigeria. The research study covered 24 manufacturing industries spread across the two states under study. The respondents comprised 177 management staff and 1488 factory workers. A 45 items questionnaire structured on a 5-point Likert scale response options were used to collect data from the respondents. The research instrument was validated by five research experts, one each from; the department of Technology Education, Federal University of Technology, Minna and Abubakar Tafawa Balewa university, Bauchi; Department of Vocational Teacher Education, University of Nigeria, Nsukka; Safety department of Nigeria National Petroleum Corporation, Kaduna and Training Department of Industrial Training Fund, Zonal Office, Minna and corrections were made appropriately before it

was administered. The data obtained from the respondents were analyzed using Mean $(\bar{X})$ and Standard Deviation (S.D). Therefore, items with mean score below 3.00 were regarded as disagreed while those with mean score of 3.00 and above were regarded as agreed. 


\section{Research Question 1}

What are the industrial safety education training needs of the industrial workers in Kaduna and Niger states of Nigeria?

Table 1

Mean $(\bar{X})$ Responses and Standard Deviation (S.D) of Management Staff and Factory Workers on Industrial Safety Education Training Needs of the Industries in the States.

\begin{tabular}{lllll}
\hline S/N & ITEMS & $X$ & SD & REMARK
\end{tabular}

1. Workers need to be familiar with safety regulations of the industry to $4.32 \quad 0.96 \quad$ Agree avoid industrial accident.

2. Workers need periodic re-orientation on the care and uses of the $4.49 \quad 1.01 \quad$ Agree machines and equipments to prevent accident.

3. Workers of industry need to know how and why they use protective $4.42 \quad 1.05 \quad$ Agree clothing in accident prevention.

4. Keeping the working environment free from obstacles to

$4.39 \quad 1.03 \quad$ Agree

Prevent accident is an area needed by the workers.

$0.98 \quad$ Agree
accidents.

6. Old employed workers need refresher on safety regulations to serve 4.35 as a reminder.

7. On the job training is the best method of safety instructions to $4.27 \quad 1.04$ Agree workers.

8. Types of accidents recorded in the industry are areas needed for $4.03 \quad 0.94$ Agree safety training.

9. First aid and medical attention are areas workers need training on.

10. General safety and health provisions will help in reducing accidents 4.17 in the industry.

11. Occupational health and environmental control are needed to reduce 4.09 accidents

12. Personal protective and life saving equipment are matters that require 4.24 the attention of workers.

13. Fire protection and prevention materials are good materials in 4.32 preventing industrial accidents.

14. Signs and signals when identified by workers can prevent accident training.

The data presented in table 2 showed that both categories of staff agreed with the 15 items with mean score ranging from $4.03-4.49$. The respondents agreed that the 15 items should be part of the training needs in the industries in industrial safety education programme in order to reduce accidents while working.

\section{Research Question 2}

What are the potential sources of industrial accidents in workshops/laboratories of manufacturing industries? 
Table 2

Mean $(\bar{X})$ Responses and Standard Deviation (S.D) of Management Staff and Factory Workers on the potential sources of Industrial Accident in Workshops/Laboratories of Manufacturing Industries.

$\begin{array}{lllll}\text { S/N } & \text { ITEMS } & X & \text { SD } & \text { REMARK }\end{array}$

1 Inadequate machine guarding contributes to industrial accident $\quad 445 \quad 098$ Agree

2. Defective condition of equipment can cause industrial accident. $\quad 4.43 \quad 1.01 \quad$ Agree

3. Lack of signs, signals and barricades in the factories are sources of $\quad 4.44 \quad 1.05 \quad$ Agree industrial accident.

4. Improper use of mechanical aids such as jigs and fixtures are sources $\quad 4.41 \quad 1.03 \quad$ Agree of industrial accident.

5. Special lifting devices whose maximum load capacities are $4.24 \quad 0.90 \quad$ Agree exceeded.

6. Power tools not properly grounded and insulated do cause accident.

$4.16 \quad 0.92 \quad$ Agree

7. Floors, aisles, and inside passageways not kept clean.

$4.44 \quad 0.94 \quad$ Agree

8. Protective clothing such as gloves, protective shoes amongst others when not used.

9. Incompetent personnel operating industrial equipment.

$4.22 \quad 1.01 \quad$ Agree

10. All fixed machinery not securely anchored to prevent movement.

11. Poor handling of industrial equipment is source of accident.

13. Negligence to safety rules while working in the industries.

14. Improper illumination in the factories is a source of accident.

15. Poor safety awareness, education and safety training.

4.16 $\quad 0.92 \quad$ Agree

4.35 $\quad 1.01 \quad$ Agree

$4.46 \quad 1.03 \quad$ Agree

The data in table 2 revealed that the management staff and factory workers agreed that all the 15 items presented to them are potential sources of industrial accidents in workshops/laboratories of manufacturing industries. 


\section{Research Question 3}

What are the suitable instructional methods to be used by the industries to ensure safety and accident prevention?

Table 3

Mean $(\bar{X})$ Responses and Standard Deviation (S.D) of Management Staff and Factory Workers on Suitable Instructional Methods used in Safety Education Programme and Accident Prevention.

\begin{tabular}{lllll}
\hline S/N & ITEMS & $X$ & SD & REMARK
\end{tabular}

1. Safety and accident prevention procedures are done through $4.24 \quad 0.97 \quad$ Agree individualized instruction.

2. Safety education programme is done through the use of public $4.24 \quad 1.01$ Agree relation activities.

3. Safety education programme to workers is done by enforcement of $3.90 \quad 1.05 \quad$ Agree the regulations.

4. Accident prevention and safety education programme is achieved by $4.27 \quad 1.03 \quad$ Agree the management through workshops and seminars

5. Lectures are mostly used by the industry in passing information on $2.80 \quad 1.50 \quad$ Undecided safety programme.

6. Safety instructions to the workers are better done by the industrial 4.40 based teachers.

3.90

$1.10 \quad$ Agree

8. Formal classroom situation is the best way for safety education 3.77 programme in the industry.

9. Safety education programme through constant coaching of the 4.34 workers can reduce accident.

10. Interactive multimedia through shop demonstration can prevent $3.97 \quad 0.94$ Agree accidents.

11. Safety instruction through shop demonstration can prevent accidents. 4.24

$0.90 \quad$ Agree

12. Public lecture by safety experts on safety in the industry can be 4.14 frequently used.

13. Field trips and conferences on safety are necessary to prevent 4.24 accidents.

14. Use of television programmes can aid in preventing industrial 4.15 accidents. safety education programme.

The data in table 3 revealed that all items presented were accepted by the respondents as suitable instructional methods used in safety education programme and accident prevention in industries except item number 5 with a mean of 2.80 in which the management staff and factory workers were undecided. 


\section{Discussion of Findings}

The results on table 1 indicated that the 15 items identified in the instrument were accepted by both categories of staff as being the areas of needs for their industrial safety education programme. Their mean responses ranged between 4.03 to 4.49 , which is high. It therefore mean that the respondents agreed with all the items as such believed the items are the industrial safety education training needs of industry workers. The workers attitude were mostly influenced by motivation received from the management on safety and machine maintenance practices, accidents prevention practices and getting the gang way free of obstacles as these items recorded very high mean ratings. In support of this finding are the works of Godbey (1979) and Miller (1998) who observed that for any meaningful safety education programme to take place, the needs of the workers must be ascertained before any safety training commences. Also Mewis (1995) point out that there are various ways of determining the training needs of the workers; these include using instruments such as survey, questionnaires, and personal interviews to gather data. This finding is in line with Miller (1998), as the training needs of the industrial workers could be determined through the administration of questionnaires. It is therefore expected that needs assessment would be carried out by industries to determine areas of need before embarking upon any safety education and accident prevention programme to achieve maximum success.

Once the needs have been determined, training objectives must be developed and written down. These objectives must be stated in terms of what employees should know and be able to do by the end of the training. If these are done, safety education programmes would go a long way in reducing and preventing accidents in the industry. Even though the findings showed that the industries have some safety and accident prevention programmes in place, it is the view of the researcher that those accident prevention programmes may not be elaborate and that is why the workers agreed that these items should be part of their training needs for safety education programme.

The results on sources of accident shown in table 2 reveals that the staff agreed that the items identified are all sources of accident in the industries. It therefore means that they are all potential hazards which if not properly handle by workers can cause accidents which could lead to injury or death. But if the workers are aware of these potential hazards and sources of accidents through safety education programme, accidents could be prevented or reduced. This finding is similar to that of Miller (1998), and Ofuonye (2004) who stated that the cause of industrial accidents could be traced to two things. It could be traced to unsafe physical conditions, e.g inadequate mechanical guarding, defective condition of equipment, unsafe design and construction, poor machine operation and arrangement, and lack of protective clothing and equipment. It could also depend on unsafe environmental conditions which include noise, heat, vibration, radiation, toxic materials, dust, gases, physical and chemical hazards. The finding implies that industries need to provide safe physical and environmental conditions for its workers to prevent accidents in the industries.

Findings as evident from the study in table 3 showed that both categories of staff agreed with all the items presented to them as suitable instructional methods of safety education programme with the exception of item number 5. The respondents disagreed with lecture methods as a method mostly used by the industry in safety education programme. Both the management staff and factory workers were unable to make decision on the use of lecture method by industries in passing information on safety programme. It therefore means that the industries, do not use lecture method in accident prevention programme perhaps because of the business nature of the industries, it may be difficult to organize such lectures by the management. This is contrary to what Miller (1998) said, that traditional lecture method of instruction may be the best way to impart any information on safety and accident prevention.

However, Strong (1975), Boyd (1978) and Riggs (1981) are of the opinion that safety education programme can take many forms. It may include classroom method, discussions, field trips, shop demonstration and talks, etc. They went further to say that the programme will depend on multitude of factors, such as time, money, number of employees and the business climate. The industries should, therefore, analyze and see the methods that best suit their environment for a meaningful safety education. This is in line with Rodriques (1990) who said that, industries should insist on formal, fully organized and documented safety education programme, which is designed to develop awareness of safe and healthful practices to the workers based on industries, resources and employee awareness.

\section{Conclusion}

High production output, smooth manufacturing operations and high profit maximization can only be achieved when the industrial activities continue smoothly and safely without interruption or excess downtime resulting from loss or accident to human, machines, tools, equipments and materials. Therefore management staff of manufacturing industries have to put in place a functional industrial safety education programme where workers will be taught and trained about the various hazards inherent in industrial materials, tools, equipments 
and machines. Factory workers should be trained to observe all safety precaution while working to prevent accident and injury so as to create a safe and conducive working environment for all categories of staff in the manufacturing industries in the Northeastern states of Nigeria.

\section{Recommendation}

Based on the findings of the study, the following recommendations were made:

1. Each manufacturing industry should have a comprehensive safety education and accident prevention programme in place for its workers to prevent accident and injury. The yearly safety week is not adequate to keep the workers aware of the dangers of the working environment.

2. Each manufacturing industry should have a health and safety department to be responsible for all safety education programmes of the industry and also ensure the strict compliance of all safety regulations of the industry by its workers.

3. Safety department in manufacturing industries should ensure that, the management provides a conducive working environment for its workers according to the laws of the Federation.

4. Industries should take into consideration the instructional methods that best suit their industry as well as their industry's training needs in order to impart the appropriate safety attitudes in workers.

5. The Ministry of Employment, Labour and Productivity should ensure strict compliance with the Factories Act (Cap 126) of 1990 to save the lives of factory workers who are dying daily due to lack of safety education and accident prevention programme in place.

6. The Factory Acts should be reviewed to make the penalty tougher for defaulters of the Law.

7. All the industries in the country irrespective of the area of location should have a safety education programme to prevent accidents in the working environment. They should ensure that the working environment is conducive for the workers so as to avoid any health and safety problems.

8. All the manufacturing industries should employ only skilled labour and qualified staff who will be able to operate and man those equipment and machines with little or no difficulty, as it was discovered that unqualified and unskilled staff are prone to accidents more than the skilled and qualified staff.

9. Management of the manufacturing industries should show more commitment towards safety education programme by committing some of its resources to the programme so as to motivate its workers towards the programme.

\section{References}

[1] Apagu, V.V., Bulama, K.H. \& Diraso, D.K. (2000). Industrial Safety Training Programme: Curriculum Implications for Technical Schools/Colleges in Adamawa. Nigeria Journal of Educatioon and Technology, 1(1), 180-188.

[2] Atsumbe, B.N (2006). Effective Environmental Managemet through Recycling of Metallic and non Metallic Waste Management by Local Crafts Men in Minna Metropolis. Journal of Vocational and Adult Education: 6 (1): 12-22.

[3] Boyd, J.E. (1978). Equipment for Rural Workshop. London: Intermediate Technology Publication.

[4] FRN (1990). The Laws of the Federation of Nigeria: Factories Act (Cap 126). Lagos: Federal Ministry of Justice.

[5] Godbey, F.W. (1979). Occupational Safety and Health in Vocational Education: A guide for Administrators, Faculty and Staff. Washington DC; Department of Health, Education and Welfare.

[6] Hislop, R.D. (1999). Construction Site Safety: A Guide for Managing Contractors. Washington DC: Lewis Publication.

[7] Jain, R.K. (2010). Production Technology. New Delhi: Khanna Publishers.

[8] Mewis, J.J. (1995). Loss Prevention and Safety Promotion in the Processing Industries. Proceedings of the $8^{\text {th }}$ International Symposium. Antwerp, Belgium, June 6-9.

[9] Miller, K.L. (1998). Objective Based Safety Training: New York, Lewis Publishers.

[10] O’toole, M. (2003). Lone Workers: A Unique Safety Challenge. Retrieved June 20, 2004 from http//www.looksmart.com.

[11] Ofuonye, E. (2004). Factory Hands,Slave Labour. New Age Newspaper, June 3rd, 20-21.

[12] Pidgeon, N. (1998). Safety Culture Key and Theoretical Issues. Work snd Stress. 12, 202-216.

[13] Riggs, J.L. (1981). Production Systems: Planning, Analysis and Control. John Willey and Sons Inc., Newyork.

[14] Rodriques, C.C. (1990). Analysis of Subjective Response. In B.Das (Ed), Industrial Ergonomic and Safety II. London: Taylor and Francis 619-626.

[15] Strong, M.E. (1975). Accident Prevention Manual for Training Programme. A Professional Publication of the National Association of Industrial and Technical Teacher Education (NAITTE). Chicago: American Technical Society, 13-48 